\title{
Ice supersaturations exceeding $100 \%$ at the cold tropical tropopause: implications for cirrus formation and dehydration
}

\author{
E. J. Jensen ${ }^{1}$, J. B. Smith ${ }^{2}$, L. Pfister ${ }^{1}$, J. V. Pittman ${ }^{2}$, E. M. Weinstock ${ }^{2}$, D. S. Sayres ${ }^{2}$, R. L. Herman ${ }^{3}$, R. F. Troy ${ }^{4}$,

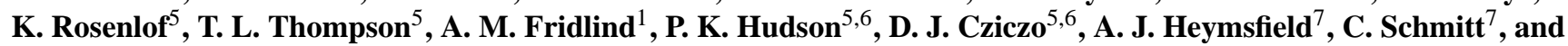 \\ J. C. Wilson ${ }^{8}$ \\ ${ }^{1}$ NASA Ames Research Center, Moffett Field, CA, USA \\ ${ }^{2}$ Harvard University, Cambridge, MA, USA \\ ${ }^{3}$ Jet Propulsion Laboratory, Pasadena, CA, USA \\ ${ }^{4}$ University of California, Los Angeles, CA, USA \\ ${ }^{5}$ Aeronomy Laboratory, National Oceanographic and Atmospheric Administration, Boulder, CO, USA \\ ${ }^{6}$ Cooperative Institute for Research in the Environmental Sciences, University of Colorado, Boulder, CO, USA \\ ${ }^{7}$ National Center for Atmospheric Research, Boulder, CO, USA \\ ${ }^{8}$ University of Denver, Denver, CO, USA
}

Received: 14 October 2004 - Published in Atmos. Chem. Phys. Discuss.: 9 November 2004

Revised: 21 February 2005 - Accepted: 27 February 2005 - Published: 14 March 2005

\begin{abstract}
Recent in situ measurements at tropical tropopause temperatures as low as $187 \mathrm{~K}$ indicate supersaturations with respect to ice exceeding $100 \%$ with little or no ice present. In contrast, models used to simulate cloud formation near the tropopause assume a supersaturation threshold for ice nucleation of about $65 \%$ based on laboratory measurements of aqueous aerosol freezing. The high supersaturations reported here, along with cloud simulations assuming a plausible range of temperature histories in the sampled air mass, indicate that the vast majority of aerosols in the air sampled on this flight must have had supersaturation thresholds for ice nucleation exceeding 100\% (i.e. near liquid water saturation at these temperatures). Possible explanations for this high threshold are that (1) the expressions used for calculating vapor pressure over supercooled water at low temperatures give values are at least $20 \%$ too low, (2) organic films on the aerosol surfaces reduce their accommodation coefficient for uptake of water, resulting in aerosols with more concentrated solutions when moderate-rapid cooling occurs and correspondingly inhibited homogeneous freezing, and (3) if surface freezing dominates, organic coatings may increase the surface energy of the ice embryo/vapor interface resulting in suppressed ice nucleation. Simulations of in situ cloud formation in the tropical tropopause layer (TTL) throughout the tropics indicate that if decreased accommodation coefficients and resulting high thresholds for ice nucleation pre-
\end{abstract}

Correspondence to: E. J. Jensen

(ejensen@cirrus.arc.nasa.gov) vailed throughout the tropics, then the calculated occurrence frequency and areal coverage of TTL cirrus would be significantly suppressed. However, the simulations also show that even if in situ TTL cirrus form only over a very small fraction of the tropics in the western Pacific, enough air passes through them due to rapid horizontal transport such that they can still effectively freeze-dry air entering the stratosphere. The TTL cirrus simulations show that even if very large supersaturations are required for ice nucleation, these large supersaturations should occur very rarely.

\section{Introduction}

Recent studies have demonstrated the importance of cold ice clouds formed in the tropical tropopause layer (TTL) for the Earth's radiation budget (Comstock et al., 2002) and regulation of the amount of water vapor entering the stratosphere across the cold tropical tropopause (Jensen et al., 1996; Holton and Gettelman, 2001; Gettelman et al., 2002; Jensen and Pfister, 2004). Understanding the processes controlling stratospheric water vapor concentration to the degree that future concentrations can be predicted is important because stratospheric water affects polar stratospheric cloud formation and ozone destruction (Toon et al., 1989; Solomon et al., 1986), gas-phase ozone destruction (Dvorstov and Solomon, 2001), and the earth's radiation budget (Forster and Shine, 2002).

(C) 2005 Author(s). This work is licensed under a Creative Commons License. 
In spite of the likely importance of these clouds, basic processes controlling the conditions under which they will form and their microphysical properties are poorly understood. In particular, the conditions under which ice crystals can nucleate near the cold tropical tropopause are not known. Previous in situ measurements of ice saturations ratios ranging from 1.1-1.7 (i.e. supersaturations of 10-70\%) near the tropical tropopause (Jensen et al., 2001) indicated that substantial supersaturations were required for ice nucleation on the majority of aerosols in this region of the atmosphere. Relatively small numbers of effective ice nuclei (IN) might also be present allowing nucleation of a few ice crystals at lower supersaturations but would not often quench supersaturation and prevent homogeneous freezing (Kärcher, 2004). Modeling studies of in situ cirrus formation generally assume (as a baseline case) that the aerosols are pure sulfuric acid, and parameterizations are used to calculate nucleation rates versus temperature, saturation ratio, and aerosol size (e.g., Koop et al., 2000). These nucleation parameterizations are based on laboratory measurements of the conditions under which homogeneous ice nucleation occurs in aqueous aerosols with a variety of compositions including sulfuric acid (e.g., Bertram et al., 1996; Koop et al., 1998).

In situ measurements of upper tropospheric relative humidity have previously been used to infer ice nucleation thresholds in a number of studies. For example, Haag et al. (2003b) used clear-sky, in-situ relative humidity measurements in the southern hemisphere and northern hemisphere midlatitude upper troposphere to infer the predominance of homogeneous freezing nucleation in the clean southern hemisphere and an important contribution from heterogeneous nucleation in the polluted northern hemisphere.

In this study, we present recent measurements indicating ice saturation ratios as high as about 2.3 can occur under cold tropical tropopause conditions without substantial ice nucleation. The implications of these measurements for ice nucleation are evaluated using simple simulations assuming a plausible range of temperature histories for the air masses prior to measurements of high supersaturations. Possible physical mechanisms allowing these large supersaturations are considered. Next, we evaluate the potential implications of these high ice nucleation thresholds for TTL cloud formation and dehydration using simulations of TTL transport and cloud formation throughout the tropics. We show that these increased thresholds result in simulated in situ cloud formation over only a very limited region in the tropics, but dehydration of air entering the stratosphere is still quite effective even though the clouds occupy a very small fraction of the tropics.

\section{Ice supersaturation measurements}

During January 2004, NASA conducted a series of flights with the WB-57 out of San Jose, Costa Rica as part of the
Pre-Aura Validation Experiment (Pre-AVE). In this analysis, we use three measurements of water vapor concentration: the Harvard water vapor instrument (HWV) photodissociates $\mathrm{H}_{2} \mathrm{O}$ molecules with $121.6 \mathrm{~nm}$ (Lyman- $\alpha$ ) radiation and detects the resulting $\mathrm{OH}$ photofragment fluorescence at $315 \mathrm{~nm}$ (Weinstock et al., 1994); the Jet Propulsion Laboratory laser hygrometer (JLH) measures absorption with a near-infrared tunable diode laser (May, 1998); the Harvard total water instrument (HTW) uses the same principles as the HWV instrument to measure total water with a front-end heater and heated duct to evaporate hydrometeors (Weinstock et al., 2005 ${ }^{1}$ ) . Pressure was measured with a Weston DPM 7885 pressure transducer and temperature with two Rosemount platinum resister probe. During the NASA Cirrus Regional Study of Tropical Anvils and Cirrus Layers-Florida Area Cirrus Experiment (CRYSTALFACE), this temperature-pressure measurement system was used along with the Meteorological Measurement System (MMS) on the WB-57 and an independent MMS system on the ER-2. The three temperature measurements agreed to within a few tenths of a K during an ER-2/WB-57 formation flight segment on 13 July, 2002.

On 29 January, the WB-57 descended across the relatively cold $(\simeq 187 \mathrm{~K})$ tropical tropopause over the Pacific south of Costa Rica. Figure 1 shows the profiles of water vapor concentration, temperature, and ice saturation ratio. The two water measurements give very similar $\mathrm{H}_{2} \mathrm{O}$ mixing ratios at altitudes below the cold-point at $17.1 \mathrm{~km}$. The measurements indicate a monotonic decrease in water vapor concentration with increasing altitude down to about $5.2 \mathrm{ppmv}$ at the coldpoint. The ice saturation ratio $\left(s_{i}\right)$ at the tropopause indicated by the water vapor and temperature measurements is about 2.3-2.4 (i.e. about $130-140 \%$ supersaturation with respect to ice). Note that the higher peak supersaturation indicated by the JLH measurement does not reflect a discrepancy between the JLH and HWV water measurements. The $1-\mathrm{Hz}$ JLH measurement simply better resolves the sharp peak in $s_{i}$ than the $0.1 \mathrm{~Hz}$ HWV measurement.

The Harvard water vapor instrument is rigorously calibrated in the laboratory before and after each deployment, and the calibration is checked by direct absorption measurements. During the 29 January flight, short term increases in water vapor in cloud-free air were encountered during ascent at about $12.5 \mathrm{~km}$ and descent at around $11.5 \mathrm{~km}$. These increases relative to background values allow for measurements of water vapor by two independent methods: photofragment fluorescence and direct absorption of Lyman$\alpha$ radiation at $121.6 \mathrm{~nm}$ using Beer's law. On ascent the maximum amount of water vapor in the feature was about 25 ppmv while on descent it was about 225 ppmv. For both features agreement between the two methods was better than

\footnotetext{
${ }^{1}$ Weinstock, E. M., Sayres, D., and Pittman, J.: Total water measurements on the WB57 aircraft in thin and thick cirrus, J. Geophys. Res., in preparation, 2005.
} 
$3 \%$ with fluorescence measuring slightly higher during the ascent feature and slightly lower during the descent feature. Hintsa et al. (1999) estimated the accuracy of the instrument to be $\pm 5 \%$.

For estimation of the supersaturation uncertainty, we use conservative estimates for the temperature and pressure uncertainties of $\pm 0.5 \mathrm{~K}$, and $\pm 0.5 \mathrm{mbar}$, respectively. Assuming a conservative $10 \%$ uncertainty in the water vapor measurement, the combined uncertainties in water vapor concentration, temperature, and pressure give an an uncertainty in saturation ratio of about $13 \%$. We have included error bars of this magnitude in Fig. 1, along with the saturation ratio thresholds for freezing of sulfate aerosols for aerosol radii of 100, 50, and $20 \mathrm{~nm}$ (Koop et al., 2000). Even if most of the sulfate aerosols at the tropopause on this flight were unusually small $(\leq 20 \mathrm{~nm})$, they should still have frozen at ice supersaturations well below those measured on this flight. One would assume that when the air cools sufficiently to drive $s_{i}$ above the threshold, aerosols will rapidly begin freezing until enough ice is generated such that deposition growth depletes the water vapor concentration and the increase in $s_{i}$ is halted or reversed. Given the large concentrations of aerosols typically present (at least $10 \mathrm{~cm}^{-3}$ and often much larger (Brock et al., 1995)), one would expect that $s_{i}$ would not significantly exceed $s_{i, n u c}$ even for brief time periods or under rapid cooling. We present modeling results below that confirm this expectation.

If rapid cooling occurs, the diffusion of water vapor to aerosols is too slow to keep the aerosol activity in equilibrium with the ambient saturation ratio with respect to supercooled liquid. This effect could allow the supersaturation to exceed the Koop threshold shown in this figure by several $\%$ (Haag et al., 2003a), but the peak supersaturations should still be well below the observed values.

Using the expressions for vapor pressure over ice and supercooled liquid recommended by Murphy and Koop (2005) at the minimum temperature of $187.1 \mathrm{~K}$, saturation with respect to liquid water occurs at an ice saturation ratio of $2.05-$ well below the peak observed value of about 2.3 , but within the range of uncertainty. Saturation ratios significantly exceeding water saturation are implausible since water drops would be activated and quench further increase in saturation. However, as discussed further below, the vapor pressure over supercooled water cannot be directly measured at these temperatures and is very uncertain. As a result, we argue that the saturation ratio measurements do not necessarily have a high bias.

The Harvard total water measurement actually indicated somewhat lower water concentrations near the tropopause than the water vapor measurements. The HTW instrument uses the same detection technique as the HWV instrument, and its laboratory calibration is identical as well. However, in order to maintain ambient particle densities in the HTW instrument, an isokinetic inlet is used that results in slower mass flow than in the HWV instrument (Weinstock et al.,

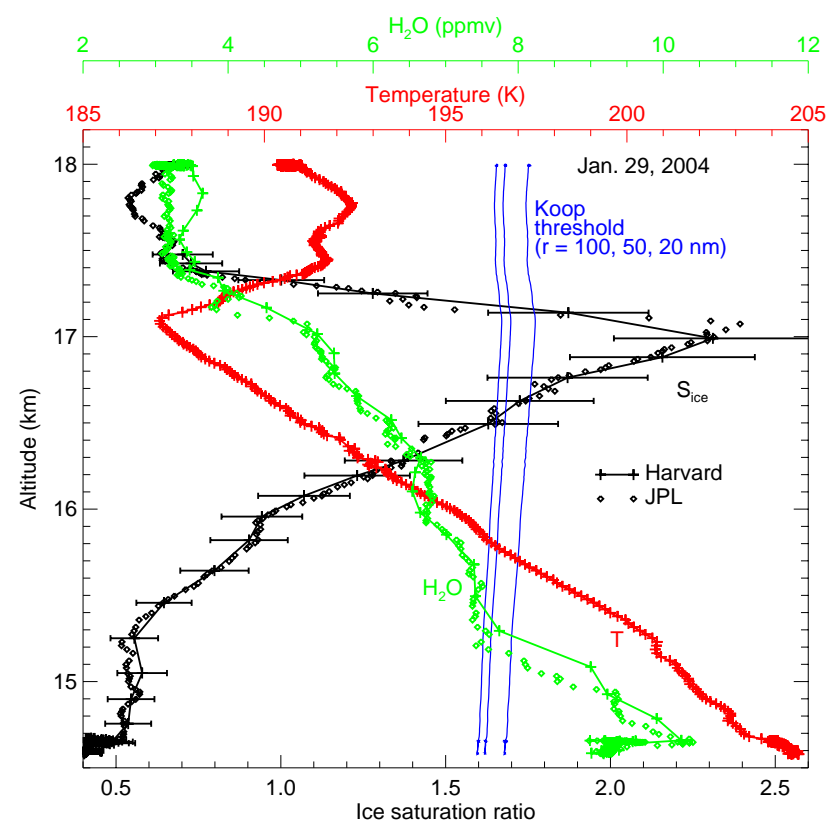

Fig. 1. In situ measurements from a WB-57 descent across the cold tropopause south of Costa Rica are shown. Ice supersaturations at the tropopause are far larger than the threshold for ice nucleation due to freezing of aqueous aerosols (in equilibrium with the ambient water vapor) indicated by a measurement-based parameterization (Koop et al., 2000) (blue curves). See text for discussion.

$2005^{1}$ ). As a result, the uncertainty in the total water measurement is larger than that for the water vapor measurement partly due to hysteresis in the total water measurement when the water concentration changes rapidly. The total water/water vapor measurements agree within their uncertainties. The lack of apparent enhancement in total water near the tropopause constrains the condensed (ice) mixing ratio to no more than about 1 ppmv.

The only direct measurements of ice crystal properties during this flight came from the Video Ice Particle Sampler (VIPS) instrument (Heymsfield and McFarquhar, 1996). The VIPS images during the cold tropopause crossing considered here indicated no ice crystals present in the detectable size range ( $\geq 10-20 \mu \mathrm{m}$ diameter) anywhere in the supersaturated layer. The VIPS noise limit is about $2 \times 10^{-5} \mathrm{~g} \mathrm{~m}^{-3}$ corresponding to about 0.2 ppmv at 90 mbar pressure. Crystals smaller than $20 \mu \mathrm{m}$ may have been present, but given the lack of condensed water in excess of water vapor and the lack of evidence for removal of water vapor at the temperature minimum, we conclude that little or no ice nucleation had occurred recently in the air sampled.

\section{Implications for ice nucleation}

In order to clarify the implications of the measurements described above, we next use a cloud model to investigate what 

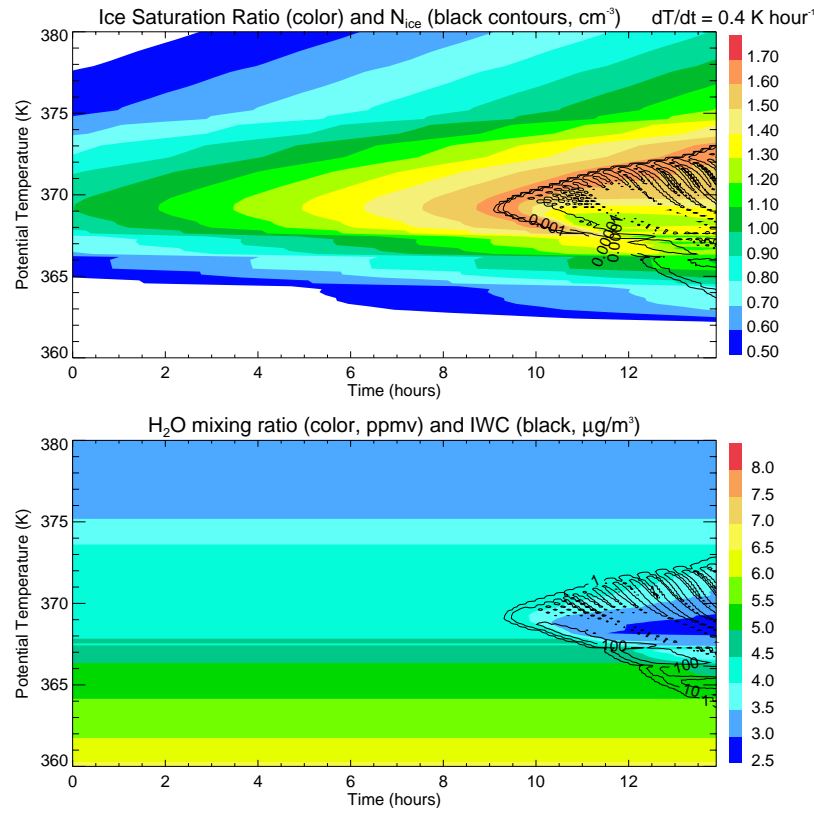

Fig. 2. Color shading shows saturation ratio (top panel) and water vapor mixing ratio (bottom panel) versus time and height for an idealized simulation with a column of air cooling over several hours leading up to the WB-57 sampling time. Location of the ice cloud is indicated by black ice number density contours. The cloud formation limits the ice saturation ratio to $\leq 1.65$ and dehydrates the region near the tropopause.

possible sequence of temperature evolution and cloud processes might have led to the observed saturation ratio profile. Rather than running back trajectories from the flight time and location, we use a more general approach of considering a range of temperature histories for the observed airmass. Since the tropopause region was observed in unusually extreme conditions of low temperature and high supersaturation, presumably the air cooled prior to the aircraft sampling. We initially assume the air cooled monotonically and explore the impact of cooling rate and aerosol freezing properties. Hence, we assume the entire column of air cooled steadily at a particular rate in the hours-days leading up to the sampling. The impact of temperature oscillations is discussed below.

For the simulation of cloud formation and $\mathrm{H}_{2} \mathrm{O}$ mass exchange between the vapor and condensed phase, we use a detailed, one-dimensional microphysical model that tracks the growth and sedimentation of thousands of individual ice crystals in a vertical column (Jensen and Pfister, 2004). Water vapor is tracked on an Eulerian vertical grid with potential temperature as the vertical coordinate. The vertical domain and grid spacing are $\theta=358-390 \mathrm{~K}$ and $d \theta=0.18 \mathrm{~K}$. This model has been used to investigate the climatological effects of TTL cirrus on water vapor (Jensen and Pfister, 2004) and for simulating TTL cirrus sampled during CRYSTAL-FACE (Jensen et al., 2004). We assume a deposition coefficient of 0.5 for calculating ice crystal growth rates (Haynes et al.,
1992). Results are insensitive to the deposition coefficient as long as values larger than about 0.1 are assumed. Coagulation of ice crystals is neglected. We use the parameterization given by Koop et al. (2000) to calculate ice nucleation rates due to aqueous aerosol freezing as a function of water activity along with the expressions recommended by Murphy and Koop (2005) for saturation vapor pressure over ice and supercooled liquid. This combination of expressions gives a threshold ice saturation ratio for ice nucleation of about 1.65 at $190 \mathrm{~K}$. Using different expressions in the literature for vapor pressure over supercooled water can give threshold ice saturation ratios as much as $20-25 \%$ higher or lower than this value. This uncertainty is discussed further below.

Within each of 25 sulfate mass bins (spanning the dry aerosol radius range from $0.01-5 \mu \mathrm{m}$ ), we keep track of the time-dependent aerosol radius, sulfate mass fraction, and activity by calculating the diffusion of water to the aerosols. The $\mathrm{H}_{2} \mathrm{O}$ saturation vapor pressure over sulfuric acid aqueous solutions is calculated using the expression given by Tabazadeh et al. (1997) (their Table 1). When very rapid cooling occurs, the diffusion of water vapor to larger aerosols is too slow to keep them in equilibrium with the vapor (Haag et al., 2003a). For the most rapid cooling rates considered below, the kinetic limitation of water uptake by aerosols can increase the peak supersaturations by $5-10 \%$.

We initialize the model with the observed water vapor mixing ratio profile and a temperature profile $5 \mathrm{~K}$ warmer than the observed profile such that the air is initially subsaturated with respect to ice. Using the measured water vapor profile is equivalent to assuming that no dehydration occurred upstream. Aerosol size distributions were measured on the WB-57 with the Nucleation-Mode Aerosol Size Spectrometer (N-MASS) (Brock et al., 2000) and Focused Cavity Aerosol Spectrometer (FCAS) instruments (Jonsson et al., 1995). Based on the measurements made during the descent, we initialized the simulations with a log-normal aerosol size distribution using a concentration of $100 \mathrm{~cm}^{-3}$, a mode radius of $0.025 \mu \mathrm{m}$, and a distribution width of $\sigma=1.4$. This assumption is actually conservative since we are effectively excluding any larger aerosols that might have been scavenged by ice nucleation upstream. The sensitivity of results to the assumed aerosol size distribution turns out to be minimal unless no aerosols larger than $10-20 \mathrm{~nm}$ are assumed to be present.

As a reasonable range of cooling rates, we use 0.04$40 \mathrm{~K} \mathrm{~h}^{-1}$, corresponding to adiabatic ascent rates of about $0.1-100 \mathrm{~cm} \mathrm{~s}^{-1}$. This range includes slow synoptic-scale motions, mesoscale motions, small-scale gravity waves, and shallow convection. Figure 2 shows the evolution of ice saturation ratio and water vapor mixing ratio in a simulation with a typical synoptic-scale cooling rate of $0.4 \mathrm{~K} \mathrm{~h}^{-1}$. As specified by the aerosol freezing parameterization, ice nucleation occurs first at the cold point when $s_{i}$ exceeds about 1.65 and subsequently above and below the cold point as the column of air continues to cool. Nucleation and deposition growth 

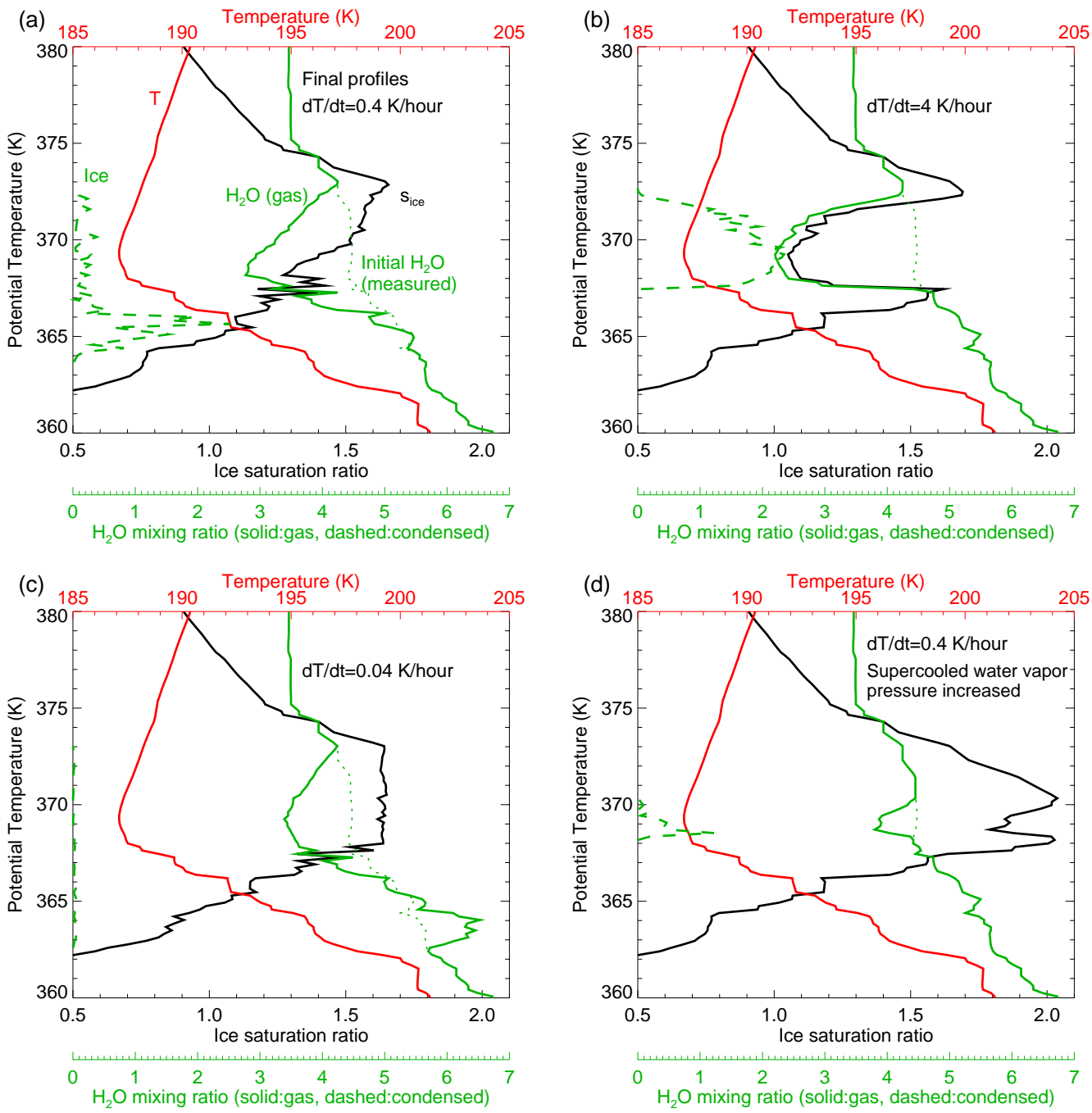

Fig. 3. Vertical profiles of temperature, water vapor concentration, ice mixing ratio, and ice saturation ratio are plotted at the end of simulations for comparison with the measured profiles shown in Fig. 1. The temperature profile at the end of each simulation is equal to measured profile. (a) Cooling rate $=0.4 \mathrm{~K} \mathrm{~h}^{-1}$; (b) cooling rate $=4 \mathrm{~K} \mathrm{~h}^{-1}$; (c) cooling rate $=0.04 \mathrm{~K} \mathrm{~h}^{-1}$; (d) cooling rate $=0.4 \mathrm{~K} \mathrm{~h}^{-1}$ and vapor pressure over supercooled water increased up to $23 \%$ (temperature-dependent) such that the $s_{i}$ threshold for ice nucleation is increased (See text for details.).

of ice crystals prevents $s_{i}$ from exceeding the 1.65 threshold significantly at any time or location in the simulation. The ice crystals grow to diameters of $20-30 \mu \mathrm{m}$ resulting in significant sedimentation. The water vapor mixing ratio is depleted in a layer centered on the cold point due to growth and sedimentation of ice crystals.

The impact of the cirrus layer on the final water vapor and saturation ratio profiles is shown in Fig. 3a. The upstream ice cloud has irreversibly dehydrated the region around the cold-point tropopause such that the ice saturation ratio peak $(\simeq 1.65$ at $\theta=373 \mathrm{~K})$ is well above the tropopause. Very little condensed mass remains at the WB-57 sampling time (no more than about 2 ppmv), and most of the ice resides near the bottom of the saturated layer well below the tropopause.
Increasing the cooling rate to $4 \mathrm{~K} \mathrm{~h}^{-1}$ results in higher ice number densities (up to a few $\mathrm{cm}^{-3}$ ) limiting crystal growth. The smaller crystals fall more slowly, and they have less time to fall since the air is cooling more rapidly; hence, most of the ice mass remains near the tropopause (Fig. 3b). At the end of the simulation, the water vapor mixing ratio profile shows significant depletion near the tropopause and condensed mass roughly equal to vapor mass, in stark contrast to the measurements. As in the simulation with a moderate cooling rate, the peak ice saturation ratio is above the tropopause and limited to about 1.7.

Decreasing the cooling rate results in correspondingly smaller ice concentrations and larger crystals. The crystals fall out of the tropopause layer before they can drive the ice 
saturation ratio down toward unity. However, the ice crystals still prevent $s_{i}$ from significantly exceeding $s_{i, n u c}$. The final profile shows a broad layer with $s_{i}$ roughly equal to this threshold value of about 1.65 (Fig. 3c). A slight enhancement of water vapor concentration due to sublimation of crystals below the supersaturated layer is apparent as well.

If cooling cycles upwind of the observed profile had driven ice nucleation events, then most of the aerosols available for ice nucleation might have been activated and removed by sedimentation, possibly allowing the ice supersaturation to build up to the observed values. To evaluate this possibility, we have run a number of simulations with temperature oscillations superimposed on a slow cooling rate. We discount this scenario for two reasons:

1. in these simulations, whenever the aerosols were depleted by ice nucleation and scavenging, the water vapor profile also showed clear evidence of dehydration (i.e. a dry layer as evident in the examples shown in Fig. 3);

2. the measured aerosol size distribution was typical with no evidence of an absence of relatively large particles.

As discussed by Murphy and Koop (2005), the vapor pressure over supercooled water at these low temperatures cannot be measured directly and is relatively poorly constrained. Most of the aerosol freezing laboratory experiments measure the water activity (assumed to be equal to the liquid water saturation ratio in equilibrium with the aerosols) at the point where ice nucleation occurs. Calculation of the threshold ice saturation ratio requires multiplication of the threshold liquid saturation ratio by a vapor pressure ratio $p_{s a t, l} / p_{s a t, i}$. Hence, one possible explanation for the high supersaturations reported here is that the vapor pressure over supercooled water is larger than that calculated by integrating the Clapeyron equation using best available estimates of supercooled water thermodynamic properties. The uncertainties in $p_{s a t, l}$ at temperatures below $190 \mathrm{~K}$ reported by Murphy and Koop (2005) are sufficient to account for the discrepancy between the ice supersaturations reported here and those inferred from laboratory measurements of the aerosol activity at which sulfate freezing occurs.

To demonstrate this effect, we multiplied our expression for $p_{s a t, l}$ by a factor $(1+0.018(200-T))$ for temperatures below $200 \mathrm{~K}$. This adjustment resulted in increasing $s_{i, n u c}$ to about 2.04 at $187 \mathrm{~K}$, such that ice nucleation would only have begun shortly before the WB-57 sampling (assuming the air was cooling prior to the observations). The resulting final profile (Fig. 3d) shows that even if $s_{i, n u c}$ is only slightly lower than the observed peak saturation ratios, then a notch in the $s_{i}$ profile results in contrast to the observed profile that was sharply peaked at the temperature minimum. Our interpretation is that the supersaturation had not quite gotten high enough to trigger ice nucleation at the time of the WB-57 decent across the tropopause.
Recent laboratory experiments with the Aerosol Interaction and Dynamics in the Atmosphere (AIDA) cloud chamber have provided direct measurements of $s_{i, n u c}$ (Möhler et al., 2003). The water vapor concentration in the cloud chamber was measured with a Lyman- $\alpha$ hygrometer allowing calculation of the ice saturation ratio threshold without use of the uncertain supercooled liquid vapor pressure. The threshold freezing rates are in approximate agreement with the Koop et al. (2000) parameterization (with an estimated uncertainty of about $10 \%$ ), suggesting that the error in the supercooled water vapor pressure may not be large. Additional laboratory experiments with direct measurement of water vapor partial pressure should be conducted to confirm the AIDA chamber results.

Another possible explanation for the observed high supersaturations is that the aerosols in the region sampled have a composition that is very different from the aerosol compositions used in laboratory freezing experiments. Although laboratory experiments with dicarboxylic acids indicate little or no effect on the activity at which aerosols freeze (Wise et al., 2004), a wide variety of organic compounds can be present in aerosols, and the issue remains open. Recent field measurements of ice nucleation onset have suggested that homogeneous freezing of aerosols may be delayed until near liquid water saturation is reached when the mass of organic components in aerosols is unusually high (DeMott et al., 2003). Further, Cziczo et al. (2004) showed that organic-rich particles preferentially remain unfrozen when ice nucleation occurs, indicating an increased barrier to freezing of these organicrich aerosols. Measurements made with the Particle Analysis by Laser Mass Spectrometry (PALMS) instrument during WB-57 flights in the tropics have shown that the tropical upper tropospheric aerosols typically have significant organic components (Murphy et al., 1998).

During the January 29 descent from about 18 to $14 \mathrm{~km}$, PALMS sampled 11 particles. Although these particles were not sampled in the narrow layer with high ice supersaturations, their composition was similar to others sampled in tropical upper troposphere/lower stratosphere region: primarily mixed sulfates with organics, a few particles contained mercury and iodine, and one particle contained potassium indicating a biomass-burning source. Hence, the available in situ measurements do not indicate that the air in the vicinity of the high supersaturation layer was necessarily atypical for the tropical tropopause region. However, relatively few particles were sampled, they were not in the specific layer of interest, and we cannot constrain the detailed chemical composition of the aerosols present.

If we assume that organics (or other impurities) and sulfates are both present and, at least to some degree, externally mixed, then a fraction of the aerosol population should freeze at supersaturations indicated by the laboratory measurements. For simplicity, we assume that some fraction of the aerosols has composition such that they freeze at supersaturations indicated by the laboratory measurements and 


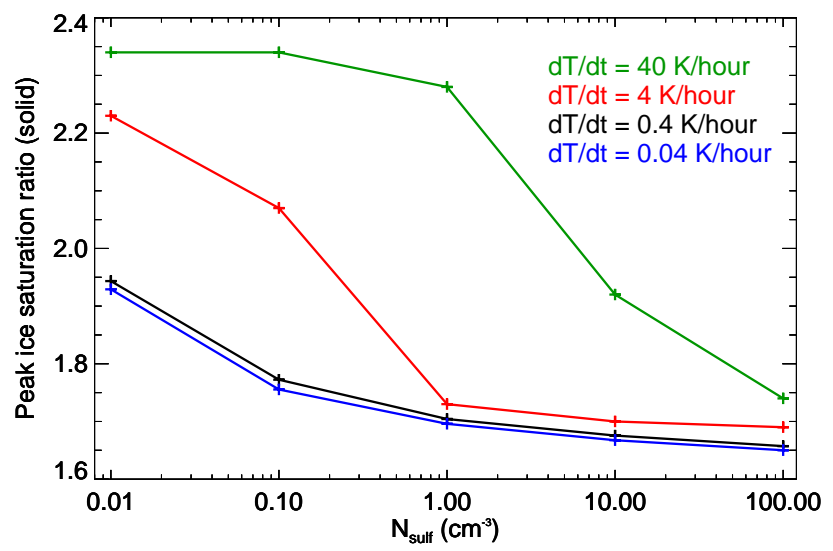

Fig. 4. Peak ice saturation ratios achieved at any location or time in simulations with different initial concentrations of sulfate aerosols and cooling rates are plotted. The range of ice saturation ratios shown here correspond to relative humidities with respect to liquid ranging from about $80-100 \%$.

that the rest of the aerosols include sufficient impurities such that they do not freeze at any supersaturation. If the number of aerosols available for ice nucleation is decreased far enough, then cooling will eventually lead to supersaturation with respect to liquid water. Once sufficient liquid supersaturations occur, liquid droplets will be activated, followed by growth, dilution, and freezing. Since we are calculating the time-dependent uptake of water by aerosols in the model, this process is treated properly.

We have run a series of simulations varying the fraction of aerosols available for homogeneous freezing. Figure 4 shows the peak ice saturation ratio achieved at any time in the simulations versus the sulfate aerosol concentration for the range of cooling rates considered. The peak ice saturation ratios only approach the measured values if the sulfate aerosol concentration is less than about $0.01-1 \mathrm{~cm}^{-3}$, depending on the cooling rate. Note that the maximum cooling rates considered here $\left(40 \mathrm{~K} \mathrm{~h}^{-1}\right)$ are extremely unlikely for the air sampled on the 29 January flight. There were no convective systems anywhere near the air sampled, and the profile shown in Fig. 1 shows no evidence of strong wave activity. The inhibition of aerosol freezing due to impurities would only permit the observed high supersaturations if the vast majority of the aerosols contained sufficient impurities to prevent homogeneous freezing.

As discussed recently by Cziczo et al. (2004) and Kärcher and Koop (2004), a plausible physical mechanism for delaying aerosol freezing is that films of organics on the surface of aerosols limits their water uptake rate by reducing the accommodation coefficient, $\alpha_{c}$. Numerous laboratory experiments have investigated the impact of surface coatings on water uptake (see Barnes, 1986; Chuang, 2003, for reviews). Even at room temperature, the impact of surface active organics on accommodation coefficients is unclear; some studies indicate that a coating reduces water uptake (Xiong et al., 1996;

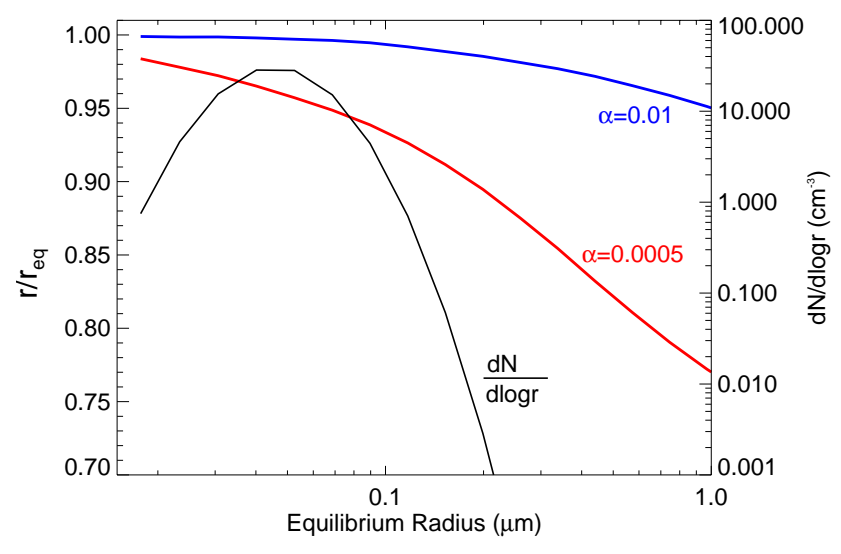

Fig. 5. The ratio of aerosol radius divided by the equilibrium radius is plotted versus equilibrium radius for different accommodation coefficients (red and blue curves). The aerosol size distribution used in the simulations is shown for reference. If $\alpha_{c}$ is significantly decreased by surface impurities, the aerosols can be much more concentrated and less likely to freeze than they would be in equilibrium with the vapor.

Chen and Lee) while other studies show little or no effect (Hansson et al., 1998; Wagner et al., 1996). However, mass accommodation coefficients as low as $10^{-5}$ to $10^{-4}$ have been measured, with the magnitude of $\alpha_{c}$ depending on the intermolecular organization of the organic films. Comparisons between predicted and measured cloud condensation nuclei concentrations during periods with high organic mass content in aerosols provide circumstantial evidence for suppressed accommodation coefficients of atmospheric aerosols (Cantrell et al., 2001). The suppression of water vapor condensation by organic films will likely be more effective at low temperature since surface films tend to take on a more solid-like state with decreasing temperature (Adamson and Gast, 1997).

To evaluate the impact of reduced aerosol accommodation coefficients, we have run a series of simulations with cooling rates of $0.4-40 \mathrm{~K} \mathrm{~h}^{-1}$ and a range of accommodation coefficients. As discussed above, we are calculating the timedependent aerosol radius and composition by calculating the diffusion of water to the aerosols. Figure 5 shows the effect of a low accommodation coefficient on the aerosol radii for the moderate cooling rate simulation $\left(4 \mathrm{~K} \mathrm{~h}^{-1}\right)$. If $\alpha_{c}$ is larger than about 0.01 , then for all sizes where significant numbers of aerosol present (less than about $0.3 \mu \mathrm{m}$ ), the aerosols are essentially in equilibrium with the surrounding water vapor. However, if the deposition coefficient is significantly suppressed ( $\alpha_{c}=5 \times 10^{-4}$ curve), the aerosols cannot take up water fast enough to stay in equilibrium. The aerosols are more concentrated than the equilibrium composition, resulting in reduced activity and reduced probability of freezing.

Confirming the results of Kärcher and Koop (2004), we find that decreasing the accommodation coefficient results in 


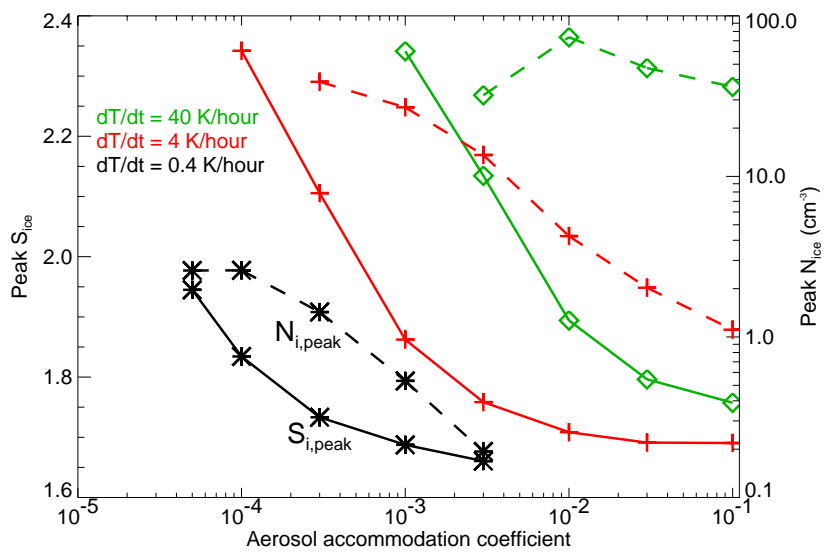

Fig. 6. The impact of reduced aerosol accommodation coefficient on peak ice saturation ratios (solid) and ice number densities (dashed) is shown for different cooling rates (colors and symbols). With rapid cooling and $\alpha_{c} \leq 8 \times 10^{-3}$, large ice supersaturations build up. Even with slow-moderate cooling, large ice supersaturations are possible if $\alpha_{c} \leq 5 \times 10^{-5}$ to $5 \times 10^{-4}$. Also, ice concentrations increase dramatically with decreasing deposition coefficient in slow-moderate cooling rate simulations.

increased peak ice saturation ratios and increased ice concentrations (Fig. 6). For the rapid cooling rate (equivalent to $1 \mathrm{~m} \mathrm{~s}^{-1}$ adiabatic ascent), simulations that are likely unrealistic for the Pre-AVE profile reported here, deposition coefficients would only need to be suppressed to values below about $8 \times 10^{-3}$ to allow supersaturations comparable to the Pre-AVE measurements to build up. Even with moderate and slow cooling (equivalent to 10 and $1 \mathrm{~cm} \mathrm{~s}^{-1}$ ), large ice supersaturations are possible if $\alpha_{c} \leq 5 \times 10^{-4}$ and $5 \times 10^{-5}$, respectively. Note also that the peak ice concentrations in the simulations with moderate-slow cooling increase rapidly with decreasing $\alpha_{c}$. When ice nucleation is initiated, the first crystals nucleated start to grow and deplete the vapor concentration. In the simulations with deposition coefficients near unity, the aerosols rapidly shrink in response to the decreasing humidity, and ice nucleation is quickly shut off. But if $\alpha_{c}$ is very small, the aerosols shrink slowly, allowing more aerosols to freeze and large ice concentrations to build up. For the smallest deposition coefficients considered here in the moderate cooling simulations $\left(\alpha_{c} \leq 0.001\right)$, a large fraction of the aerosols freeze resulting in ice concentrations exceeding $30 \mathrm{~cm}^{-3}$ and ice crystal diameters limited to a few $\mu \mathrm{m}$.

In addition to the kinetic effects on water uptake by aerosols, surface active organics may also affect the thermodynamics of ice nucleation in aqueous aerosols. If aerosol surface freezing dominates over volume freezing, then the ice nucleation rate will be very sensitive to the surface energy of the ice embryo/vapor interface (Djikaev et al., 2002; Tabazadeh et al., 2002). If surfactants increase the surface energy of this interface then surface freezing may be strongly suppressed. As with the reduce accommodation coefficient hypothesis, laboratory measurements are required to determine the plausibility of this mechanism.

\section{Implications for TTL cirrus formation}

As discussed above, simulations of cirrus formation in the upper troposphere generally assume the aerosols freeze at ice supersaturation ratios of about 1.65 as indicated by the laboratory measurements and supercooled water vapor pressure expressions. If the high ice nucleation thresholds indicated by the Pre-AVE measurements apply generally throughout the tropics, then one would expect that calculated cirrus frequencies would be reduced. Further, since air could ascend through the tropopause cold-trap having higher supersaturations without ice nucleation, the flux of water to the stratosphere should be increased.

To evaluate these effects, we use a set of cloud simulations described by Jensen and Pfister (2004). Specifically, we use the cloud model described above to simulate cirrus formation driven by "temperature curtains". The temperature curtains are generated by running isentropic back trajectories and extracting vertical profiles of temperature from the National Centers for Environmental Prediction meteorological analyses along the trajectories. Adjustments are made to account for gravity wave perturbations and tropopause temperature biases in the analyses (Jensen and Pfister, 2004). A slow upward motion $\left(\simeq 0.3 \mathrm{~mm} \mathrm{~s}^{-1}\right)$ is imposed in the simulations to balance the clear-sky radiative heating in the TTL. Several hundred simulations were run using 40-day trajectory curtains throughout the tropics for the December 1995January 1996 time period. These trajectories ended at points on a regular grid between $\pm 20^{\circ}$ latitude with $5^{\circ}$ latitudelongitude spacing allowing us to construct fields of water vapor throughout the TTL.

For this study, we have run a set of simulations with the typical aerosol freezing ice nucleation expressions, supercooled water vapor pressures, and unity mass accommodation coefficient for uptake of water by aqueous aerosols (the baseline case) as well as a set of simulations with the accommodation coefficient reduced to $5 \times 10^{-5}$ resulting in enhanced supersaturation threshold for ice nucleation when moderate-rapid cooling occurs. Cloud frequencies and tropopause water vapor concentrations from these sets of simulations are shown in Fig. 7. Increasing the threshold for ice nucleation substantially decreases calculated cloud frequencies. The peak cloud frequencies are decreased from about $40 \%$ to $20 \%$, and, more significantly, cloud formation in the $\alpha_{c}=5 \times 10^{-5}$ set of simulations is restricted to the western Pacific. Throughout most of the tropics, the temperatures never get cold enough to drive the ice saturation ratio above the increased threshold. The air sampled during PreAVE (Fig. 1) provides an example of this situation. No detectable cloud was present, but if the ice nucleation threshold 
(a) Baseline $\left(\alpha_{c}=1\right)$

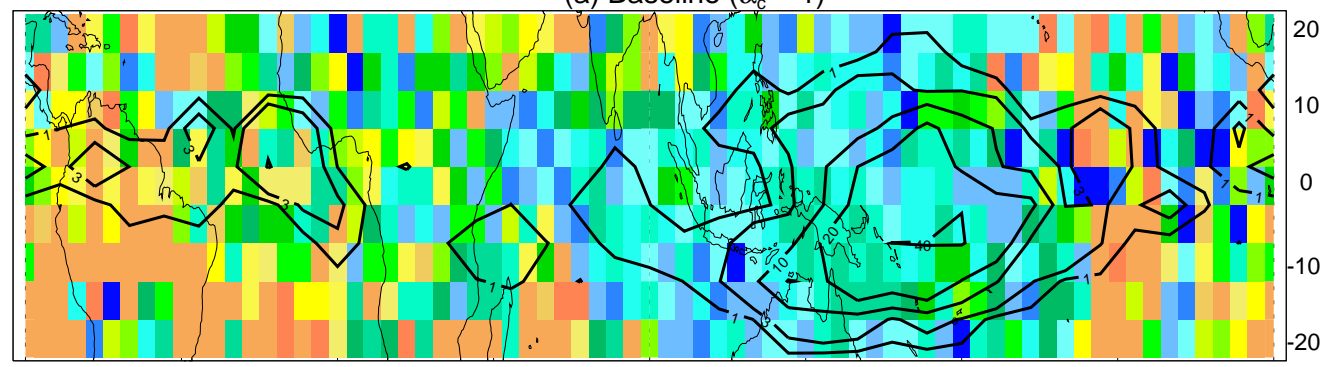

(b) $\alpha_{c}=5 \times 10^{-5}$
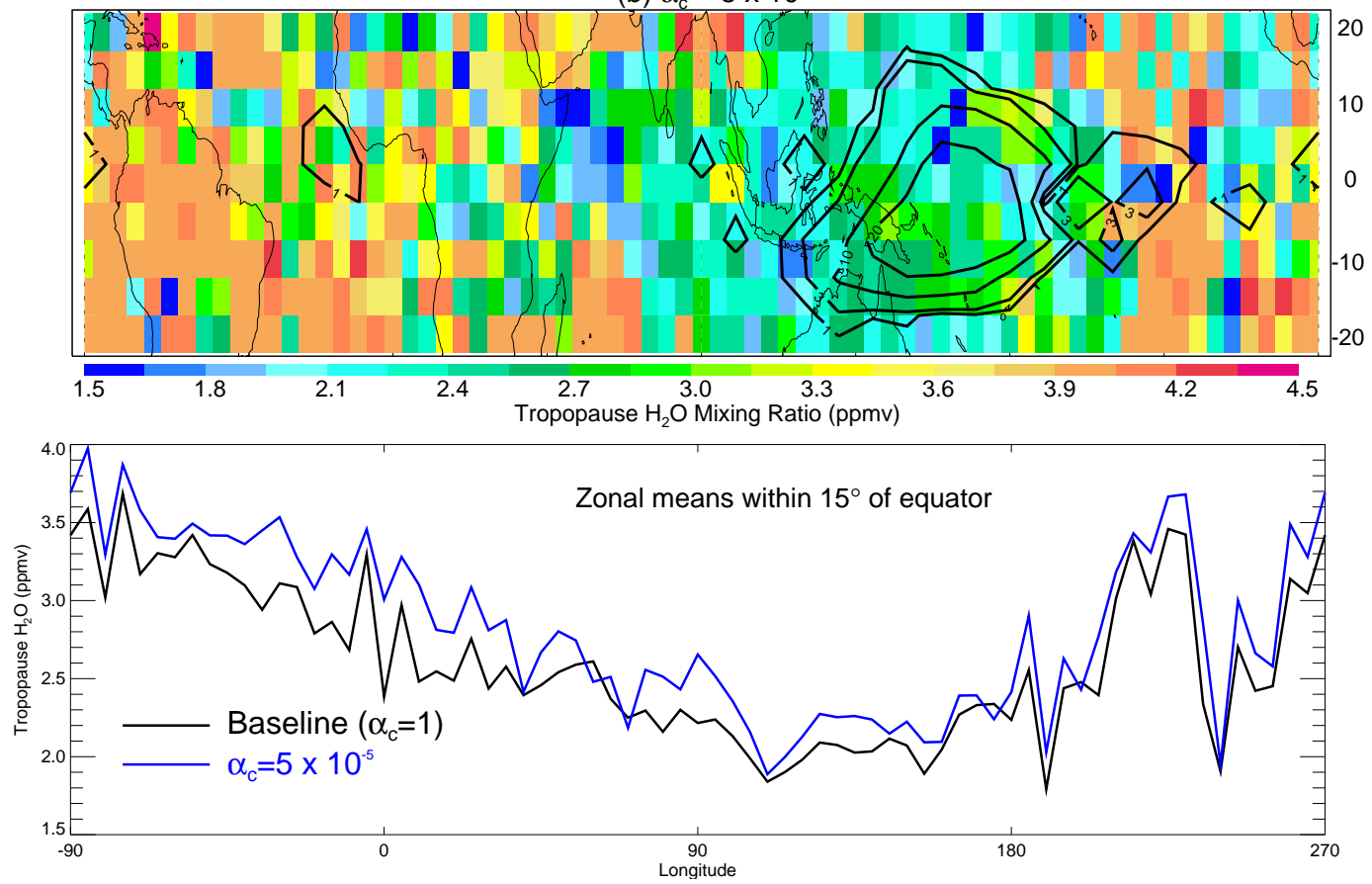

Fig. 7. The top two panels show the simulated tropical distribution of tropopause water vapor concentration and cloud frequency. The color shading indicates the water vapor mixing ratio at $380 \mathrm{~K}$ potential temperature at the end of the trajectory simulations, and the black contours are the cloud frequencies from the entire 40-day simulations. Increasing the threshold for ice nucleation by decreasing the mass accommodation coefficient for uptake of water by aerosols (middle panel) decreases peak cloud frequencies by more than a factor of 2 and restricts the region where clouds form to the western Pacific. On the other hand, the final tropopause water vapor concentrations are only slightly affected by the change in nucleation threshold as shown in the bottom panel.

had been lower, then a cloud necessarily would have formed. Note, however, that the occurrence of high supersaturations in the simulations is rare: saturation ratios greater than $170 \%$ occur less than $2 \%$ of the time. Hence, it is perhaps not surprising that the relatively small number of past in situ TTL relative humidity measurements have not revealed such high supersaturations.

Somewhat surprisingly, the final tropopause $(\theta=380 \mathrm{~K})$ water vapor concentrations are only slightly affected by the increase in nucleation threshold. Averaged throughout the tropics, the tropopause mixing ratio increases less than $10 \%$, and in the driest regions, there is little or no change. Transport of air through the relatively small western-Pacific region, where clouds form, effectively flushes the water, re- sulting in dry parcels reaching $380 \mathrm{~K}$ over a large fraction of the tropics.

\section{Conclusions}

We have presented in situ measurements from the Pre-AVE mission indicating unexpectedly high supersaturations with respect to ice at low temperatures in the absence of an ice cloud. Along with cloud simulations, the measurements lead to the conclusion that the vast majority of the aerosols present were highly resistant to ice nucleation via homogeneous freezing or any other mechanism. In particular, the ice saturation ratio thresholds for homogeneous freezing of 
available aerosols must exceed $s_{i, n u c} \simeq 2.3$ at temperatures approaching $T \simeq 187 \mathrm{~K}$ (near saturation with respect to liquid water), whereas parameterizations based on laboratory measurements of sulfate aerosol freezing give $s_{i, n u c} \simeq 1.65-1.75$, depending on the aerosol size distribution and cooling rate. Both of the WB-57 in situ water vapor measurements would need to be reduced by at least $25 \%$ for consistency with the laboratory $s_{i, n u c}$ values. This offset is well beyond the experimental uncertainties. Although anecdotal, these measurements suggest that expressions used for ice nucleation calculations in cloud simulations may need to be revised for such cases.

The Pre-AVE flights were not the first measurements of ice saturation ratio at the tropical tropopause. During past airborne science missions, the NASA ER-2 aircraft has occasionally made ascents and descents across the tropical tropopause. These profiles indicated substantial ice supersaturations near the tropopause but not the extreme supersaturations reported here (Jensen et al., 2001). However, the highest supersaturations are likely to be transient events occurring only in very cold air just before ice nucleation occurs, and, as discussed above, simulations along trajectories indicate that these high supersaturations occur very rarely.

In addition, several balloon-borne frostpoint hygrometer soundings were made during March 1988 and April 1989 and January 2004 from San Cristobal (Vömel et al., 2002), which is very near the location of the WB-57 profile reported here. In none of these profiles were ice saturations exceeding $\simeq 1.5$ observed. A long-standing and yet to be resolved discrepancy between the balloon-borne frost-point hygrometers that made these measurements and the aircraft hygrometers used in this study has been reported previously (Oltmans and Rosenlof, 2000). The Harvard and JPL instruments generally give water vapor concentrations about $15-30 \%$ (or about 1 ppmv at stratospheric values) higher than the balloon-borne cryogenic measurements. If this difference represents a systematic high bias in the Harvard and JPL water vapor measurements, this could explain the discrepancy with laboratory measurements of ice nucleation thresholds. However, this explanation would require that the two aircraft measurements exhibit systematic errors yielding a virtually identical high bias for completely different physical reasons, and it disregards the well-documented calibration and validation of the WB-57 instruments.

It should be noted that very large ice supersaturations have previously been reported from satellite limb-sounding microwave measurements (Spichtinger et al., 2002). Determination of the relative humidity frequency distribution from Microwave Limb Sounder measurements is problematic given the relatively poor precision of the MLS relative humidity retrieval (Jensen et al., 1999). However, the Spichtinger et al. (2002) analysis showed that the slope of the relative humidity frequency distribution did not noticeably change at about $160 \%$ suggesting that larger supersaturations did indeed exist.
Three possible explanations for the high nucleation thresholds were discussed. First, most of the laboratory experiments measure the water activity at which sulfate aerosols freeze. Calculation of $s_{i, n u c}$ from the liquid water saturation ratio threshold requires multiplication by the vapor pressure over supercooled liquid. The supercooled water vapor pressure is not directly measured at these temperatures and is poorly constrained. $\mathrm{A} \simeq 20 \%$ increase in $p_{\text {sat }, l}$ over currently used values would be consistent with the high ice supersaturations measured here. However, the recent AIDA chamber experiments provide direct measurements of $s_{i, n u c}$ values also well below those inferred from the Pre-AVE measurements. Additional laboratory experiments with direct measurements of the water vapor concentration at the point of homogeneous ice nucleation in aqueous aerosols are needed to confirm the AIDA experiment results.

Second, we explored the possibility that ice nucleation might be inhibited because organic films on the aerosol surfaces hinder the uptake of water in rapidly cooling air. We showed that if the accommodation coefficient is suppressed to values below about $5 \times 10^{-5}$ to $8 \times 10^{-3}$, depending on the cooling rate, then aerosols cannot take up water fast enough to stay in equilibrium. Hence, they remain more concentrated, with lower activities, and lower freezing probability, allowing ice supersaturations to build up to the observed values. We also found that peak ice concentrations increase rapidly with decreasing deposition coefficient due to the reduced rate of aerosol activity decrease when ice crystals begin to nucleate.

Third, if surface freezing dominates ice nucleation in aqueous aerosols, surface active organics might increase the energy of the ice embryo/vapor interface, resulting in strongly suppressed ice nucleation. Additional laboratory and field measurements are required to explore this possibility.

The latter two of these hypotheses suggest that aerosol composition inhibits ice nucleation. Our simulations indicate that in order to allow the supersaturation to build up to the observed values, the vast majority of available aerosols would need to be resistant to homogeneous freezing.

Simulations of TTL transport and cloud formation throughout the tropics show that the increased nucleation threshold would have a large impact on the calculated frequency and regional coverage of thin cirrus formed in situ within the TTL. In particular, the simulated TTL cloud formation is limited to the western Pacific cold-pool region. Lidar measurements have documented the presence of laminar cirrus apparently formed in situ elsewhere in the tropics (Pfister et al., 2001; Winker and Trepte, 1998). However, the simulations presented here do not include injection of ice or water vapor into the TTL by deep convection. Massie et al. (2002) used trajectory analysis to show that about half of the thin cirrus in the TTL can be traced back to deep convective origins within five days. In many of these cases, deep convection may have provided a source of water vapor to the 
tropopause region followed by cooling downstream resulting in in situ cloud formation. Hence, we anticipate that inclusion of a deep convective water vapor source in the simulations will increase the frequency and geographic coverage of in situ TTL cirrus.

Unexpectedly, the concentration of water vapor in air crossing the tropopause is only slightly increased by the high supersaturation threshold for ice nucleation and corresponding reduction in cloud frequency. It turns out that even a relatively confined cloud-formation region over the western Pacific can effectively freeze-dry air entering the stratosphere since a large fraction of air parcels pass through the western Pacific cold region at some time during their slow ascent through the TTL.

It should be noted that we only have a single profile across the tropical tropopause indicating the high supersaturations with respect to ice. The tropical tropopause region has been sampled in situ with accurate water vapor and temperature instrumentation only very rarely. Additional in situ measurements at cold tropopause conditions are required to evaluate whether the high supersaturation threshold for ice nucleation inferred from the Pre-AVE measurements is typical.

Acknowledgements. We are grateful for helpful discussions with B. Toon, M. Tolbert, B. Kärcher, and H. Vömel. This work was supported by NASA's Radiation Science Program and Atmospheric Chemistry Modeling and Analysis Program.

Edited by: U. Lohmann

\section{References}

Adamson, W. and Gast, A. P.: Physical Chemistry of Surfaces, Wiley and Sons, Inc., New York, 1997.

Barnes, G. T.: The effects of monolayers on the evaporation of liquids, Colloid Interface Sci., 25, 89-200, 1986.

Bertram, A. K., Patterson, D. D., and Sloan, J. J.: Mechanisms and temperatures for the freezing of sulfuric acid aerosols measured by FTIR extinction spectroscopy, J. Phys. Chem., 100, 23762383, 1996.

Brock, C. A., Hamill, P., Wilson, J. C., Jonsson, H. H., and Chan, K. R.: Particle formation in the upper tropical troposphere: A source of nuclei for the stratospheric aerosol, Science, 270, 1650-1653, 1995.

Brock, C. A., Schröder, F., Kärcher, B., Petzold, A., Busen, R., and Fiebig, M.: Ultrafine particle size distributions measured in aircraft exhaust plumes, J. Geophys. Res., 105, 26 555-26567, 2000.

Cantrell, W., Shaw, G., Cass, G. R., Chowdhury, Z., Hughes, L. S., Prather, K. A., Guazzotti, S. A., and Coffee, K. R.: Closure between aerosol particles and cloud condensation nuclei at Kaashidhoo Climate Observatory, J. Geophys. Res., 106, 28711-28 718, 2001.

Chen, Y.-Y. and Lee, W.-M. G.: .

Chuang, P. Y.: Measurement of the timescale of hygroscopic growth for atmospheric aerosols, J. Geophys. Res., 108, doi:10.1029/2002JD002757, 2003.
Comstock, J. M., Ackerman, T. P., and Mace, G. G.: Ground based remote sensing of tropical cirrus clouds at Nauru Island: Cloud statistics and radiative impacts, J. Geophys. Res., 107, doi:10.1029/2002JD002203, 2002.

Cziczo, D. J., DeMott, P. J., Brooks, S. D., Prenni, A. J., Thomson, D. S., Baumgardner, D., Wilson, J. C., Kreidenseis, S. M., and Murphy, D. S.: Observations of organic species and atmospheric ice formation, Geophys. Res.Lett., 31, doi:10.1029/2004GL019822, 2004.

DeMott, P. J., Cziczo, D. J., Prenni, A. J., Murphy, D. M., Kreidenweis, S. M., Thomson, D. S., and Borys, R.: Measurements of the concentration and composition of nuclei for cirrus formation, Proc. of National Acad. Sci., 100, 14 655-14 660, 2003.

Djikaev, Y. S., Tabazadeh, A., Hamill, P., and Reiss, H.: Thermodynamic conditions for the surface-stimulated crystallization of atmospheric droplets, J. Phys. Chem., 106, 10 247-10 253, 2002.

Dvorstov, V. L. and Solomon, S.: Response of the stratospheric temperatures and ozone to past and future increases in stratospheric humidity, J. Geophys. Res., 106, 7505-7514, 2001.

Forster, P. M. F. and Shine, K. P.: Assessing the climate impact of trends in stratospheric water vapor, Geophys. Res. Lett., 29, 10-14, 2002.

Gettelman, A., Randel, W. J., Wu, F., and Massie, S. T.: Transport of water vapor in the tropical tropopause layer, Geophys. Res. Lett., 29, 10.1029/2001GL013818, 2002.

Haag, W., Kärcher, B., Schaefers, S., Stetzer, O., Möhler, O., Schurath, U., Krämer, M., and Schiller, C.: Numerical simulations of homogeneous freezing processes in the aerosol chamber AIDA, Atmos. Chem. Phys., 3, 195-210, 2003a.

Haag, W., Kärcher, B., Ström, J., Minikin, A., Lohmann, U., Ovarlez, J., and Stohl, A.: Freezing thresholds and cirrus cloud formation mechanisms inferred from in situ measurements of relative humidity, Atmos. Chem. Phys., 3, 1791-1806, 2003 b.

Hansson, H.-C., Rood, M. J., Koloutsou-Vakasis, S., Hämeri, K., Orsini, D., and Weidensohler, A.: $\mathrm{NaCl}$ aerosol particle hygroscopicity dependence on mixing with organic compounds, J. Atmos. Chem., 31, 321-346, 1998.

Haynes, D. R., Tro, N. J., and George, S. M.: Condensation and evaporation of $\mathrm{H}_{2} \mathrm{O}$ on ice surfaces, J. Phys. Chem., 96, 85028509, 1992.

Heymsfield, A. J. and McFarquhar, G. M.: On the high albedos of anvil cirrus in the tropical Pacific warm pool: Microphysical interpretations from CEPEX and Kwajalein, Marshall Islands, J. Atmos. Sci., 53, 2424-2451, 1996.

Hintsa, E. J., Weinstock, E. M., Anderson, J. G., May, R. D., and Hurst, D. F.: On the acuracy of in situ water vapor measurements in the troposphere and lower stratosphere with the Harvard Lyman- $\alpha$ hygrometer, J. Geophys. Res., 104, 8183-8189, 1999.

Holton, J. and Gettelman, A.: Horizontal transport and dehydration of the stratosphere, Geophys. Res. Lett., 28, 2799-2802, 2001.

Jensen, E. J. and Pfister, L.: Transport and freeze-drying in the tropical tropopause layer, J. Geophys. Res., 109, doi:10.1029/2003JD004022, 2004.

Jensen, E. J., Toon, O. B., Pfister, L., and Selkirk, H. B.: Dehydration of the upper troposphere and lower stratosphere by subvisible cirrus clouds near the tropical tropopause near the tropical tropopause, Geophys. Res. Lett., 23, 825-828, 1996.

Jensen, E. J., Read, W. G., Mergenthaler, J., Sandor, B. J., Pfister, L., and Tabazadeh, A.: High humidities and subvisible cir- 
rus near the tropical tropopause, Geophys. Res. Lett., 26, 23472350, 1999.

Jensen, E. J., Pfister, L., Ackerman, A. S., and Tabazadeh, A.: A conceptual model of the dehydration of air due to freeze-drying by optically thin, laminar cirrus rising slowly across the tropical tropopause, J. Geophys. Res., 106, 17 273-17 252, 2001.

Jonsson, H. H., Wilson, J. C., Brock, C. A., Knollenberg, R. G., Newton, R., Dye, J. E., Baumgardner, D., Borrmann, S., Ferry, G. V., Pueschel, R., Woods, D. C., and Pitts, M. C.: Performance of a focused cavity aerosol spectrometer for measurements in the stratosphere of particle size in the $0.06-2.0 \mu \mathrm{m}$ diameter range, J. Tech., 12, 115-129, 1995.

Kärcher, B.: Cirrus clouds in the tropical tropopause layer: Role of heterogeneous ice nuclei, Geophys. Res. Lett., 31, doi:10.1029/2004GL019774, 2004.

Kärcher, B. and Koop, T.: The role of organic aerosols in homogeneous ice formation, Atmos. Chem. Phys., 5, 703-714, 2004.

Koop, T., Ng, H. P., Molina, L. T., and Molina, M. J.: A new optical technique to study aerosol phase transitions: The nucleation of ice from $\mathrm{H}_{2} \mathrm{SO}_{4}$ aerosols, J. Phys. Chem., 102, 8924-8931, 1998.

Koop, T., Luo, B., Tsias, A., and Peter, T.: Water activity as the determinant for homogeneous ice nucleation in aqueous solutions, Nature, 406, 611-614, 2000.

Massie, S., Gettelman, A., and Randel, W.: The distribution of tropical cirrus in relation to convection, J. Geophys. Res., 107, doi:10.1029/2001JD001293, 2002.

May, R. D.: Open-path, near-infrared tunable diode laser spectrometer for atmospheric measurements of $\mathrm{H}_{2} \mathrm{O}$, J. Geophys. Res., 103, 19 161-19 172, 1998.

Möhler, O., Stetzer, O., Schaefers, S., Linke, C., Schnaiter, M., Tiede, R., Saathhoff, H., Krämer, M., Mangold, A., Budz, P., Zink, P., Schriner, J., Mauersberger, K., Haag, W., Kärcher, B., and Schurath, U.: Experimental investigation of homogeneous freezing of sulphuric acid particles in the aerosol chamber AIDA, Atmos. Chem. Phys., 3, 211-223, 2003.

Murphy, D. M. and Koop, T.: Review of the vapor pressure of ice and supercooled water for atmospheric applications, Quart. J. Roy. Meteor. Soc., in press, 2005.

Murphy, D. M., Thomson, D. S., and Mahoney, M. J.: In situ measurements of organics, meteoritic material, mercury, and other elements in aerosols at 5 to 19 kilometers, Science, 282, 16641669, 1998.

Oltmans, S. J. and Rosenlof, K. H.: Data Quality, in: SPARC Assessment of Upper Tropospheric and Stratospheric Water Vapour, edited by: Kley, D., Russell, J. M., and Phillips, C., World Climate Research Program, 2000.
Pfister, L., Selkirk, H. B., Jensen, E. J., Schoeberl, M. R., Toon, O. B., Browell, E. V., Grant, W. B., Gary, B., Mahoney, M. J., Bui, T. V., and Hintsa, E.: Aircraft observations of thin cirrus clouds near the tropical tropopause, J. Geophys. Res., 106, 97659786, 2001.

Solomon, S., Garcia, R. R., Rowland, F. S., and Wuebbles, D. J.: On the depletion of Antarctic ozone, Nature, 321, 755-758, 1986.

Spichtinger, P., Gierens, K., and Read, W.: The statistical distribution law of relative humidity in the global tropopause region, Meteorol. Z., 11, 83-88, 2002.

Tabazadeh, A., Toon, O. B., Clegg, S. L., and Hamill, P.: A new parameterization of $\mathrm{H}_{2} \mathrm{SO}_{4} / \mathrm{H}_{2} \mathrm{O}$ aerosol composition: Atmospheric implications, Geophys. Res. Lett., 15, 1931-1934, 1997.

Tabazadeh, A., Djikaev, Y. S., and Reiss, H.: Surface crystallization of supercooled water in clouds, Proc. of National Acad. Sci., 99, $15873-15878,2002$.

Toon, O. B., Turco, R. P., Jordan, J., Goodman, J., and Ferry, G.: Physical processes in polar stratospheric ice clouds, J. Geophys. Res., 94, 11359-11380, 1989.

Vömel, H., Oltmans, S. J., Johnson, B. J., Hasebe, F., Shiotani, M., Fujiwara, M., Nishi, N., Agama, M., Comejo, J., Paredes, F., and Enriquez, H.: Balloon-borne observations of water vapor and ozone in the tropical upper troposphere and lower stratosphere, J. Geophys. Res., 107, doi:10.1029/2001JD000707, 2002.

Wagner, J., Andrews, E., and Larson, S. M.: Sorption of vapor phase octanic acid onto deliquiescent salt particles, J. Geophys. Res., 101, 19533-19540, 1996.

Weinstock, E. M., Hintsa, E. J., Dessler, A. E., Oliver, J. F., Hazen, N. L., Demusz, J. N., Allen, N. T., Lapson, L. B., and Anderson, J. G.: New fast response photofragment fluorescence hygrometer for use on the NASA ER-2 and the Perseus remotely piloted aircraft, Rev. Sci. Instrum., 22, 3544-3554, 1994.

Winker, D. M. and Trepte, C. R.: Laminar cirrus observed near the tropical tropopause by LITE, Geophys. Res. Lett., 25, 33513354, 1998.

Wise, M. E., Garland, R. M., and Tolbert, M. A.: Ice nucleation in internally mixed ammonium sulfate/dicarboxylic acid particles, J. Geophys. Res., 109, doi:10.1029/2003JD004313, 2004.

Xiong, J. Q., Zhong, M., Fang, C., Chen, L. C., and Lippmann, M.: Influence of organic films on the hygroscopicity of ultrafine sulfuric acid aerosols, Environmental Science and Technology, 23, 2145-2148, 1996. 